\title{
Mutual Understanding Determinants for Effective Communication in Business and IT Strategic Alignment Planning
}

\author{
Nurul 'Izzati Mohmad Adnan ${ }^{\# 1}$, Dian Indrayani Jambari ${ }^{\# 2}$

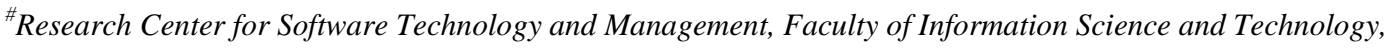 \\ Universiti Kebangsaan Malaysia, 43600, Bangi, Selangor, Malaysia \\ E-mail: ' $i z z a t i . a d n a n 07 @ g m a i l . c o m,{ }^{2}$ dian@ukm.edu.my
}

\begin{abstract}
Business and IT strategic alignment is continuously explored from different facets motivated by the demands for an organisation to be well aligned with its business and IT strategies for business continuity. The management aspect rather than technological issues often cause misalignment in business and IT strategies more significantly. One of the issues is the communication ineffectiveness between business and IT people involved in planning the business and IT strategic alignment. Difficulty to achieve mutual understanding between these two teams is a critical problem in communication and hinders the successful alignment. Therefore, a set of determinants for mutual understanding is proposed. Extensive analysis on literature has been carried out to identify and define the determining factors. The review can serve as a reference for business and IT executives to improve their communication effectiveness towards achieving well-aligned business and IT strategic alignment.
\end{abstract}

Keywords - strategic alignment; social dimension; communication; IT and business executives; convergence and mutual understanding

\section{INTRODUCTION}

Alignment between business and IT can be vertically defined into three different organizational levels: Strategic, Tactical and Operational [1]. Each level can be viewed horizontally into Human, Social and Intellectual dimensions [2]. The interwoven vertical and horizontal views of the business and IT alignment create complex multi-dimensional perspectives for organisation. Hence, it motivates extensive and broad initiatives for managing business and IT alignment.

It is imperative for Business and IT to be aligned in all three levels and dimensions of an organisation [3], [4], [5], [6]. However, it is important to firstly establish the Strategic alignment as it drives the overall business and IT alignment of the organisation [7]. Zooming into the Business and IT strategic alignment through the three dimensions in Schlosser et al. [2], the Social dimension is focused, as misalignment is more likely caused by social aspect in people rather than technology [8]. The dimension looks into the relationships and the cognitive linkages between the human actors involved in the business and IT domains and the aspects that play a role in the work relationship between business and IT.

Moderating social factors by IT and business managerial roles have impact in gaining IT business competitive advantage [9]. Social dimension has also been identified to be one of the challenges for business and IT executives to establish business and IT alignment [10], [11]. The involvement of business and IT people to gain mutual understanding of each other's domain knowledge and linkages of business and IT planning process is highly dependent on effective communication [12]. Therefore, effective communication plays an important role in forming successful alignment between IT and business domain [10].

Ineffective communication intensifies the complexity in reaching mutual understanding between business and IT teams that is crucial for a cohesive strategic business and IT alignment [13]. Lack of organized and planned approach to support effective communication between business and IT people impose higher risks to misalignment of the business and IT strategies [14]. The determining factors to achieve mutual understanding are still unclear. Discovering the factors can potentially support business and IT executives to effectively communicate with each other towards achieving mutual understanding in planning the business and IT strategic alignment. It can assist them to focus on real problems and manage disagreements effectively that are preventing them from achieving alignment [15].

Therefore, this article proposes a set of determining factors for achieving mutual understanding between the business and IT people during the communication process in planning business and IT strategic alignment. The factor identification process involves extensive analysis on 
literature in strategic alignment planning; social dimension of strategic alignment; communication and mutual understanding between business and IT executives. Complementing the factors are specific criteria defined according to each factors. The determinants facilitate the communication process in planning the business and IT strategic alignment.

The paper is organised as follows. First, the foundation of the study is discussed. Next, the process to identify and define the determining factors is presented. The review is then discussed and concluded highlighting the implication, limitation and the future work.

\section{MATERIALS AND METHODS}

\section{A. Organizational Layers of IT and Business Alignment}

The alignment of IT and Business in an organization can be distinguished into Strategic, Tactical and Operational organizational layers that consist of specific targets and characteristics [1]. Fig. 1 illustrates the three organizational layers and the positioning of business and IT domains that reflects their alignment levels according to the layers.

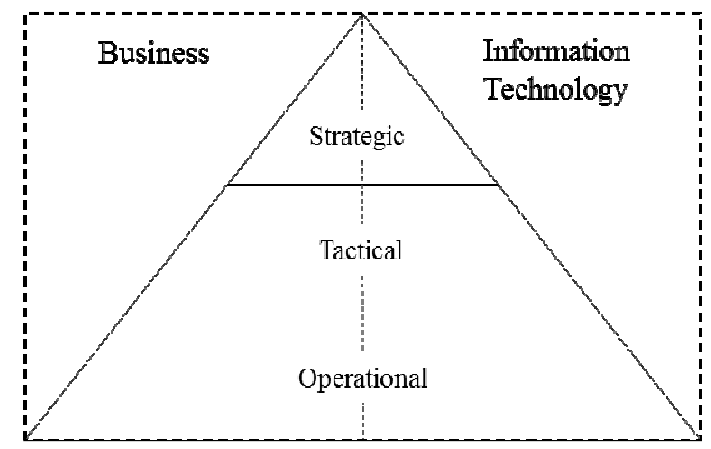

Fig. 1 Representation of the business and IT alignment according to the three organizational layers

The Strategic alignment involves the objectives of planning and linking between the IT strategy and business strategy [1]. It involved high level executives in contributing and influencing the business and IT strategic alignment planning that reflects future direction of the organization. Strategic alignment evolves with the advancement of technology. At the core, it is a two-way link of cooperation between the IT and Business strategy designed to support each other .

Strategic alignment consists of the Strategic Fit and Functional Fit of the external and internal aspects of the organisation [1]. External aspect concerns with the choices and decision relating to the relationship and alliance with individuals or units beyond the boundary of the organisation. While, the internal aspect focuses on achieving the functional aspect of the organization necessary for achieving the organization competencies consisting of IT and Business mission, objectives and plans [12]. The Strategic Fit considers both external and internal aspects, while the Functional Fit focuses on the internal aspect. Well aligned business and IT strategies benefits the organization in sustaining tough competitive market, increasing business value, returning higher investment on IT investment, and contributing to the overall business achievement [16].
Tactical alignment occurs when IT professionals' resource allocation imperatives, project selection and execution priorities, and technology choice decisions are aligned with those of organizational functional areas [17]. It intersects between the Strategic and the Operational level, deploying and facilitating the strategies from the Strategic level to be implemented in the Operational level [1].

A well plan business and IT strategies will not be effective if the organization overlook the Tactical level. Failure of alignment between IT and business in this level lead to failed execution of the IT and Business Strategic plan and negatively impacts the IT investment [17].

Operational alignment is "the set of planned managerial mechanisms to translate Strategic alignment into action" [18]. The success of the executed strategies in the Operational Alignment determines the effectiveness of the Strategic level [15].

\section{B. Dimensions in Strategic Alignment}

Apart from viewing business and IT alignment from the organizational levels, each level can also be viewed in three dimensions, Intellectual, Social, and Human. Fig. 2 shows the dimensions of the Strategic Level. The alignment dimensions are reconsidered to be viewed horizontally while the organizational layers of the alignment can be viewed vertically [2].

Intellectual dimension on the alignment consists of identifying and defining the components, processes and materials that requires strategic thinking and planning [2]. It stresses on the formalized aspects of documenting the decision-making, and technologies of performing the strategic plan.

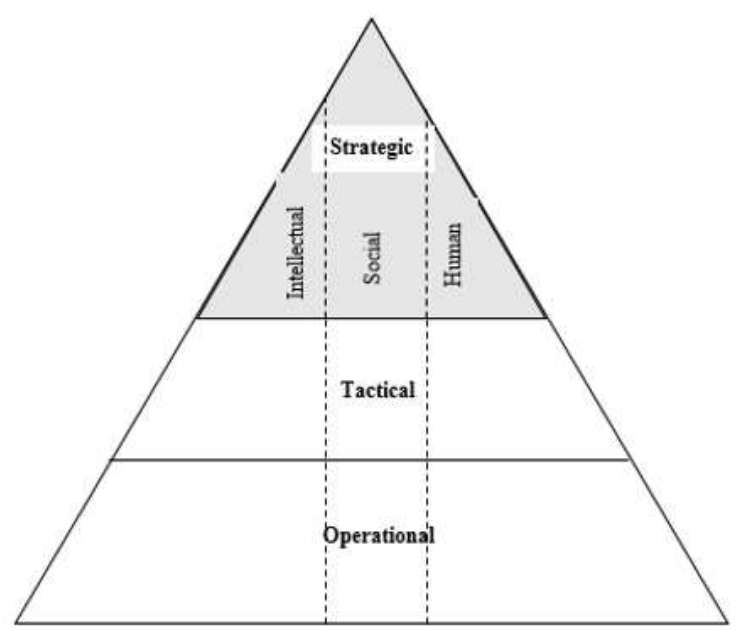

Fig. 2 The three dimensions of the Strategic Level

Social dimension focuses on performing alignment through the connection and relationship of the actors. There are four aspects that influence the Social dimension; communication between the IT and Business executives, IT and Business planning process, shared domain knowledge between IT and business executives and IT success history [12]. These aspects emphasis on the relationship and connection process required for the business and IT people in planning strategic alignment. Social dimension in the Strategic level is important in the communication process as it includes the relationship and interaction of the Business 
and IT executives involved in the strategic alignment planning process [2].

Human dimension deals with the human asset, human IT resources, skills and competencies that needs to be mastered by the IT and business people involved in the alignment process [2]. The dimension focuses on the individual involved in the alignment process, which is different from the social dimension that focuses on the relationships, mutual understanding, and cultural issues of the people.

\section{Communication for IT and Business Executives}

Mutual understanding, communication and relationship are among the main elements in the Social dimension of strategic alignment [2], [12]. The communication involves conversation or spoken communication between business and IT strategy executives. Effective communication requires both parties to perceive each other's perspective to "understand each other, sustaining their judgements and creates facts that make sense"[19]. It requires business and IT executives to be competent conversationalist in order to ensure mutual understanding between each other is achieved [20]. In turn, the mutual understanding enables the realisation of organizational objectives set in both business and IT strategies.

According to Roses et al. [19], it is important for both business and IT executives to practice effective listening and productive explanation activity. Both activities are vital to minimize incidents of misunderstanding towards the meaning of the information being communicated. It is crucial to control such incidents to avoid disagreement and conflicts between the business and IT executives. Any disagreement or conflict that can negatively impact the quality of the strategic alignment that drives the Functional Fit, as defined in Henderson and Ventakraman [1]. The mutual understanding of the strategies enables its strategic alignment planning to be effective and deployable [12]. Therefore, the executives in both domains that are listening in the communication process are required to be diligent and careful in verifying the information relayed to be accurate according to the intent of the speaker [21].

Apart from the listening and explanation concepts, conversational competence also includes commitment [22]. Commitment is relevant as it establish the linking between business and IT particularly at the strategic level where business and IT is committed to support and sustain strategic objectives and technological investment plans. The conversational competence is important because IT and business executives should use the experiences, values, skills and attitude to converse effectively with their counterpart apart from only being a good listener and talker [23].

The Conversational Competences Model described in Roses et al [19] established the validity of the effective communication being influenced by commitment concept and supported by good judgements and conflict resolution to strongly impact the strategic conversations involved in aligning business and IT. Fig. 3 depicts the concepts and its relationship in the model.

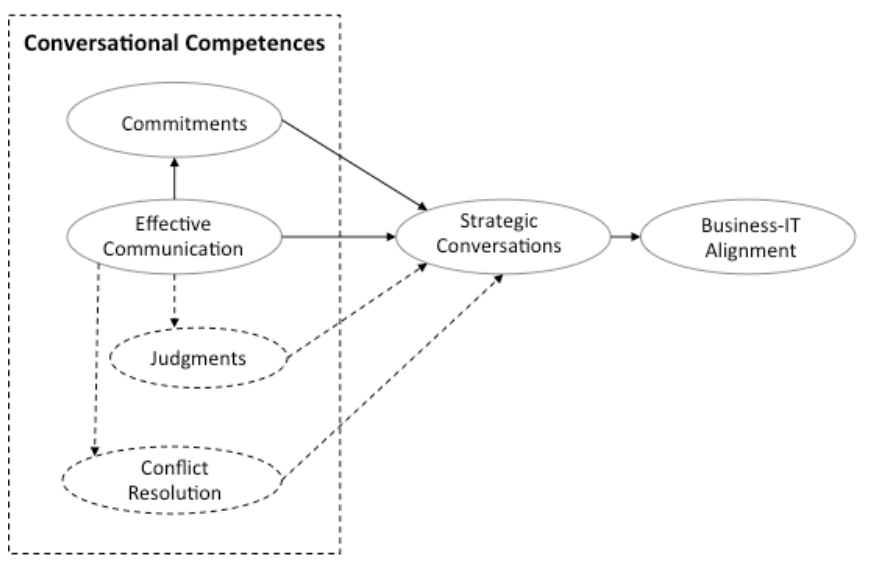

Fig 3 Conversational Competences Model for business-IT strategic alignment in Roses et al. [20]

In order for the effective communication between the business and IT strategic teams to be realized, an agreed language that is common to both teams is crucial. It enables them to articulate each other's perspective accurately and timely [24] The common language is the shared semantics of the vocabulary in the communication process, and is established through mutual understanding between the business and IT executives.

\section{State of Convergence and Mutual Understanding}

Effective communication between business and executives occurs when the executives move towards the state of convergence to achieve mutual understanding [25], [12]. The state of convergence is defined as a state when two or more people coming together and move towards a single point of unity in a common interest, focus, goal oriented and purpose [25].

While moving towards the state of Convergence, the business and IT executives are able to understand and influence each other to support its strategic plan [1], [12]. The convergence state in business and IT strategic alignment planning is formed when the executives understand each other's strategies [26]. However, "no man's interpretation of words is based on exactly the same experience as any other man's" [27]. Therefore, achieving a complete mutual understanding is impossible. Within the concept of convergence, the level of understanding between the communicators could be formed during the process of conveying their message, which includes the process of information sharing.

Information is an important element of communication and is requires to be shared between the participants to achieve the state of convergence [25]. Adapting the definition, the model depicted in Fig. 4 [25] that shows information processing must be initiated within the involved individual and includes the activities of perceiving the received information, interpreting what they understood and expressing their thoughts to the other participant. Information processing must also be performed during the communication that involves both participants as they go through cycles of information exchange leading towards the state of convergence. 


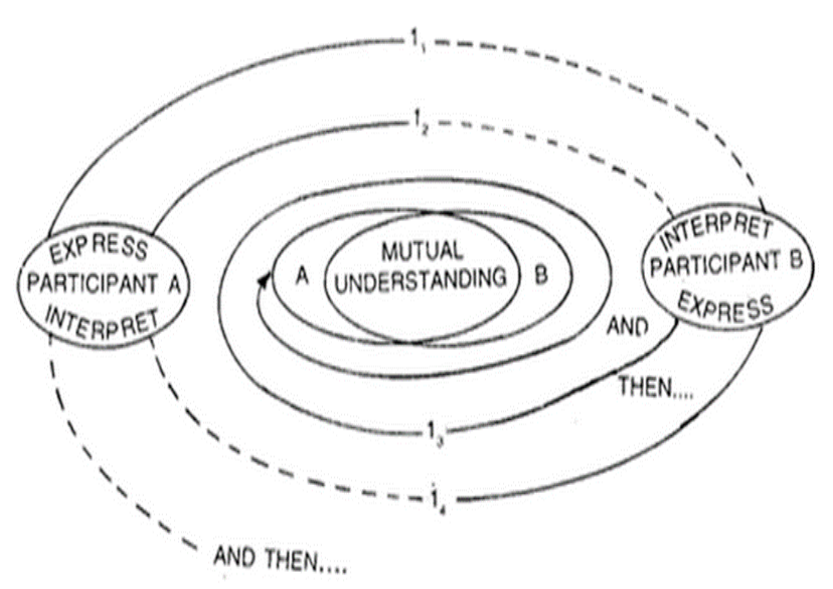

Fig. 4 The model of convergence in Kincaid and Rogers [25]

The component of mutual understanding in the Model of Convergence illustrates that mutual understanding between the participants in both domains can be formed when the state of convergence is reached. The cycle of information exchange activities by both participants will eventually make their information overlap, and determine the primary goal of the communication process [25]. It ensures that both sides of the participants have a common understanding of the importance of the discussed issue [28].

\section{E. Research Design}

Qualitative approach is adopted to identify determining factors to achieve mutual understanding during the business and IT teams communication process for strategic alignment planning. Only published and reviewed resources were selected as data source to ensure confidence for verified and validated analysis. The collection process was performed according to time periods and the scope of the study. After pre-processing, 43 published articles have been selected for analysis. The selected articles are relevant within four scopes, Business and IT strategic alignment, social dimension, effective communication and mutual understanding.

Content Analysis was implemented to identify specific themes. We extracted 40 communication criteria for mutual understanding between the business and IT executives. The criteria are classified according to similarities of meanings and functions, which resulted in seven dominant classes. The classes are verified from the literature and defined to represent determining factors for mutual understanding. However, certain criteria are found to overlap, therefore further analysis has been carried out resulting in reduced 26 criteria into four determining factors.

\section{RESULTS AND DISCUSSION}

Four determining factors have been identified to attain mutual understanding between business and IT executives in their communication process for aligning business and IT strategies. Each factor has a set of specific criteria to complement its description and practical value to the business and IT executives. Table 1 lists the factors and criteria, and described in the following discussion.
TABLE I

MUTUAL UNDERSTANDING DETERMINING FACTORS FOR IT AND BUSINESS EXECUTIVES TO EFFECTIVELY COMMUNICATE IN STRATEGIC ALIGNMENT PLANNING

\begin{tabular}{|c|c|c|}
\hline Factors & Criteria & References \\
\hline $\begin{array}{l}\text { Semantics } \\
\text { (language) } \\
\text { and mental } \\
\text { model }\end{array}$ & $\begin{array}{l}\text { - Common language } \\
\text { - Language quality } \\
\text { - IT comprehension of } \\
\text { business environment } \\
\text { requirements } \\
\text { - Understanding of } \\
\text { opposite domain's mental } \\
\text { model }\end{array}$ & $\begin{array}{l}{[23],[29],} \\
{[10],[30],} \\
{[31],[32],[2]}\end{array}$ \\
\hline Environment & $\begin{array}{l}\text { - Environment of trust } \\
\text { - Provide informal/formal } \\
\text { communication platforms }\end{array}$ & $\begin{array}{l}\text { [10], [33], } \\
{[15],[19],[34]}\end{array}$ \\
\hline $\begin{array}{l}\text { Shared IT } \\
\text { and } \\
\text { Business } \\
\text { Domain } \\
\text { Knowledge }\end{array}$ & $\begin{array}{l}\text { - Increase direct interaction } \\
\text { - Effective } \\
\text { telecommunication tools } \\
\text { - Frequent communication } \\
\text { - Openness } \\
\text { - Easy and clear } \\
\text { presentation of } \\
\text { technological issues } \\
\text { - Appoint an effective } \\
\text { liaison among each } \\
\text { domain } \\
\text { - Multilayered } \\
\text { organizational } \\
\text { involvement }\end{array}$ & $\begin{array}{l}{[10],[33],[8],} \\
{[15],[31],} \\
{[35],[12],} \\
{[16],[36],} \\
{[37],[38],} \\
{[39],[40],} \\
{[41],[42]}\end{array}$ \\
\hline $\begin{array}{l}\text { Relationship } \\
\text { Management }\end{array}$ & $\begin{array}{l}\text { - Good communication } \\
\text { - } \text { Kkills } \\
\text { work nature } \\
\text { - Good group } \\
\text { communication attitude } \\
\text { - Give positive feedback } \\
\text { - Willingness to receive IT } \\
\text { executives' opinion } \\
\text { - Maintain/increase the } \\
\text { credibility and reliability } \\
\text { of the IT management } \\
\text { - IT committed to support } \\
\text { and sustain Business } \\
\text { strategic objectives } \\
\text { Business committed to } \\
\text { invest in technological } \\
\text { infrastructure } \\
\text { - Business and IT domain } \\
\text { recognize own limitation } \\
\text { and aligned commitments } \\
\text { to the organization } \\
\text { - } \text { - } \text { Able to negotegic objectives } \\
\text { and adopt with } \\
\text { information } \\
\text { organdapt } \\
\text { mission and objectives }\end{array}$ & $\begin{array}{l}{[8],[16],[31],} \\
{[35],[19],[23],} \\
{[30],[43],[10],} \\
{[44],[37],[45]}\end{array}$ \\
\hline
\end{tabular}




\section{A. Semantics (Language) and Mental Model}

The difference in language semantics used by the business and IT executives in their communication process makes it difficult for each other to reach an agreed understanding. For instance, the practice of IT executives to communicate using technical terms may not be easily and directly comprehended by the business people [10], [33]. Concurrently, unrealistic and ambiguous description of business needs by business executives also creates misunderstanding [23]. According to the executive's domains, the semantics are also influenced by the different perspectives and thought process known as mental models [23]. Therefore, it is important for Business and IT executives to achieve common understanding in the language and mental model of both IT and business domains [33].

Both domains must consider establishing common language through agreed commonly defined terms and their respective context [19], [46]. The ability for the IT and business executives to communicate in a common language allows them to be in the same mental model [33],[23]. Understanding of mental model needs to be established in order to communicate easily and achieve better understanding of the business and IT roles in the organization [31], [10], [29], [32], [30]. The success of common language is influenced by its quality. Language quality is determined by completeness, meaningfulness, nonredundancy, unambiguity and relevance [29], [47]. Ensuring the business and IT executives to present their message or information in a common language and good quality enables mutual understanding.

\section{B. Environment}

Environment plays an important role in influencing the state of communication [33]. Appropriate environment in providing effective communication between the business and IT domains during their strategic alignment planning promotes freedom for the executives to communicate their opinions and ideas in a flexible and informal way, reducing the interaction gaps between the IT and business at the strategic level [10], [19].

In the environment, trust must exist among the executives of both domains to encourage expression of ideas and influence them to listen to each other during communication [10], [33], [38]. It is also important to provide an environment that promotes formal and informal communication network. Informal network allows the executives to express their thoughts in a simple and spontaneous way and also forms openness [10]. It also encourages the formation of a shared language and lead to mutual understanding [31]. Formal network must also exist in order for the executives from both domains to form strategic plan structurally [10], [31].

\section{Shared IT and Business Domain Knowledge}

Shared domain knowledge can be defined as the knowledge that both business and IT domains have of each other to support the forming of agreement and mutual understanding [8], [28]. Shared domain knowledge reduces the information gap between both domains in terms of the processes and goal objectives [35]. This enables better strategy development and alignment especially relating to the decision making of IT in the organization [10], [35].

Shared domain knowledge involves direct interaction between the business and IT executives that enables access to the right and necessary information required during the strategic alignment planning [10]. The frequency of interaction between both domains increases the amount of knowledge and information shared and promotes mutual confidence in the organization's business and IT strategies [36].

Effective telecommunication tools can help to render the transmission of the information between the business and IT executives [33], [38]. The effectiveness of the medium for the communication channel influence the amount of transmitted information communicated between them, their ability to provide feedback with each other and also increases the likelihood to achieve mutual understanding or state of convergence [36].

It is important for the communication line to be uninterrupted in order to ensure crucial information is not overlooked during the process. The smoothness of the communication process requires the business and IT domains to be open, especially the openness regarding the IT capability and constraint in order for the business executives to have a correct understanding of IT. The openness needs to also allow business executives to express their problems and business process openly to the IT executives [10], thus increase the transparency between the relationships of both domains to share information [31].

Appointing a representative from both domains to be the liaison or champion can facilitate the efficiency of knowledge and information sharing between the domains [20]. The liaison will not be appointed as a sole representative of their domain, but to act as a knowledge integrator to facilitate the process of creating accurate and correct understanding of the communicated knowledge and information to their other domain team members [39], [40]. The liaison's focus can differ based on their position in the organizational level. In the business domain, the Strategic level liaison can facilitate by providing the information required to guide the IT strategy based on the strategies of the business Strategic plan [41]. As for IT, the liaison can ensure the business planning conforms to the capability IT service and suitable support for the business needs right from the early phases of planning [41]. Appointing the liaisons, can influence the IT and business representative to form integration during their communication and direct the other members to achieve alignment [40],[41].

In the effort towards strategic alignment between business and IT, the Strategic planning process requires multiorganizational levels involvement. The interaction of the middle and first line managers is important in order to align with the other level's planning [42]. This includes the different ranges of activities across organizational levels, and departments in order to efficiently obtain the right requirements and information [39]. The involvement of multi-levels managers throughout the organization as the knowledge and information source ensure the strategic information are distributed well to the business and IT strategy teams in the Strategic planning, and increase their likeliness to support the plan and communicate better [42]. 


\section{Relationship Management}

Relationship management is an enabler between factors that contributes to forming better communication between the IT and business executives. Maintaining a good relationship connection between the IT and business executives is proven to positively influence the planning process and improve the connection between the IT and business strategic planning [10].

To maintain good relationship between the business and IT executives, conflict resolution and prevention is required to prevent and reduce misunderstanding and misalignment of ideas that occurs during their communication in strategic planning. Conflict resolution is defined as the admission of co-responsibility of the executives in understanding each other and reached a point of balance [19].

Commitment must exist within the IT and business executives to maintain each domains support of their opposite domain's strategy [19]. Commitment is the ability of a domain to support and sustain the strategic objectives of the other domain and vice versa in order to establish common goals and joint actions between both domains. IT must be committed to support the Business strategic objectives to encourage the IT executives to have ownership to their task and foster strategic conversation, while the business executives must be committed to invest in IT technological infrastructure relating to the IT strategy in the project or organization [19].

Relationship management is the ability of Business and IT executives to act towards maintaining close working relationship with each other and form mutual understanding between them [48]. The executives must have good communication skills and form good attitude towards communication in a group focusing on the relationship aspect. This is particularly important for the IT executives that tend to overly focus on the technical aspects [31]. Good communication skills can influence the effectiveness of the executives from both domains to share knowledge with each other during their communication process and reduce their gap of strategic information between them [10], [16].

Credibility and reliability of the IT department must be maintained to increase the potential for the business executives to acknowledge and communicate their ideas with the IT executives about related IT solutions [10]. However, both domains need to recognize their own limitations and find the point of understanding between them to prevent further conflicts [19].

The business and IT executives must also respect each other and provide positive feedbacks. This reduces tension in the communication process between both executives, which positively influence the relationship and the shared domain knowledge between them [43]. To prevent conflicts, they must also be able to negotiate, and adopt information from their opposite domain, and adapt the information with the organizational needs in order to convey the right information from their interaction [23], [30], [45].

The changing nature of IT domain is vastly evolving and becoming more complex. The understanding of the evolving nature through the external perspective of the organization and their connection is needed to prevent the business domain from having unrealistic expectation from the actual IT capability [10], [31].
Judgments made by business and IT domains as part of the communication process impacts the relationship positively or negatively. It is important to reduce their negative judgment and sustain their positive judgment with each other as positive judgments prevents argumentation and influence effective communication by giving them opportunity to establish correct understanding of the information conveyed [19], [31]. Sustaining good judgment is possible by practicing clear productive explanations, productive questioning and effective listening during the communication process [19].

The four factors and 26 criteria established from the critical analysis on the data sources focused on social dimensions in business and IT strategic planning indicates the significant diversity and abstractness of the communication process between the business and IT teams. Even though business and IT strategic teams have different metrics and targets [10], they must have firm understanding of the organization's mission, vision and objectives in order to prevent conflicts and converge their communication to achieve well aligned strategies [12]. Although both domains aim is parallel in planning an aligned strategy for their organisation, the influence of subjective human values in the communication process is significant to ensure the success of the strategic alignment planning to achieve the organization's vision, mission and objectives [8].

\section{CONCLUSIONS}

The review contributes to the body of knowledge and practice in business and IT alignment by specifying and classifying the communication determinants that have not been clearly defined in the context specifically for the communication process of IT and business strategic planning. The identified determining factors enhance the significance of the social dimension value and impact in the business and IT strategic alignment. The focus on social perspective diversifies the research in business and IT alignment that is multidisciplinary in nature. Moreover, practices can potentially refer to the four identified factors identified and their criteria to facilitate the business and IT teams to achieve mutual understanding effectively during their communication process in planning the business and IT strategic alignment.

However, the work is limited in several aspects. The determinants are only verified through the reasoning based on evidence derived from formal, reviewed and published articles. These constraints are justified, as the work is the initial phase of an active research project to develop a working model for effective communication in business and IT strategic alignment.

For future work, the development of a model is proposed using the determining factors and the criteria. Validation of the model will support the validity of the factors identified and presented here. It can also potentially discover additional factors and criteria that may enhance the effective communication process in business and IT alignment.

\section{ACKNOWLEDGMENT}

This work is supported by Universiti Kebangsaan Malaysia through the Young Researcher Development Grant 
(GGPM-2014-044) and the Research Development Fund (DPP-2015-019).

\section{REFERENCES}

[1] J. C. Henderson, and N. Ventakaraman, "Strategic Alignment: Leveraging Information Technology for Transforming Organizations," IBM Systems Journal, vol. 32, pp. 472-484. 1999.

[2] F. Schlosser, T. H. Wagner, and T.Coltman, "Reconsidering the Dimensions of Business-IT Alignment," in 45th Hawaii International Conference on System Sciences Reconsidering, 2012, p. 5053-5061.

[3] M. M. Yusof, and J. Kujlis, A. Papazafeiropoulou, and L. K Stergioulas, "An Evaluation Framework for Health Information Systems: Human, Organization and Technology-fit Factors (HOTfit)," International Journal of Medical Informatics., vol. 77, pp. 386398, June. 2008.

[4] M. M. Yusof, "A Case Study Evaluation of a Critical Care Information System Adoption Using the Socio-Technical and Fit Approach," International Journal of Medical Informatics, vol. 84, pp. 486-499, July. 2015.

[5] D. Jambari, "The Significance of Intangible Elements in Measuring the Holistic Effectiveness of Business and IT Alignment," Journal of Convergence Information Technology, vol. 9, pp. 18-25, May. 2014.

[6] L. Sun, K. Liu, D. Jambari and V. Michell, "Evaluating Business Value of IT Towards Optimisation of the Application Portfolio," Journal Enterprise Information Systems, vol. 10, pp. 378-399, May. 2016.

[7] S. Charoensuk, W. Wongsurawat, and D. Khang, "Business-IT Alignment: A practical research approach," Journal of High Technology Management Research., vol. 25, pp. 132-1147. 2014.

[8] R. Kashanchi and J. Toland, "Investigating the Social Dimension of Alignment: Focusing on Communication and Knowledge Sharing," in Pro. ACIS 2008, 2008, paper 2.

[9] T. Navedo-Samper, P. Rico, E. Ferrer and I. Revera-Ruiz, "Moderating Effects of Human Factors on IT-Business Alignment and IT Effectiveness in Modern Firms," Journal of Knowledge Management, Economics and Information Technology., vol. 3, 2013.

[10] C. Alaceva and L. Rusu, "Barriers in achieving business/IT alignment in a large Swedish company: What we have learned?," Computers in Human Behavior., vol. 51, pp.715-728, Oct. 2015.

[11] J. J. Korhonen, and J. Kaidalova, "Enterprise Modelling Facilitating Business and IT Alignment Along the Social Dimension Stakeholder Intentions for Model-Based Communication and Coordination," in 2015 IEEE 17th Conference on Business Informatics, 2015, p. 1-8.

[12] B. H. Reich, and I. Benbasat, "Factors That Influence the Social Dimension of Alignment between Business and Information Technology Objectives," MIS Quarterly., vol. 24, pp. 81-113, Mar. 2000.

[13] D. L. Kincaid and W. Schramm, Fundamental Human Communication, Honolulu, East-West Communication Institute, Professional Development Module, 1975.

[14] B. Lientz, and L. Larson, Manage IT as a Business: How to achieve alignment and add value to the company, Burlington, MA: Elsevier, 2004.

[15] V. Krotov, "Bridging the CIO-CEO gap: It takes two to tango," Business Horizons., vol. 58, pp. 275-283, 2015.

[16] S. Jorfi, and H. Jorfi, "Strategic Operations Management: Investigating the Factors Impacting IT-Business Strategic Alignment," Procedia - Social and Behavioral Sciences, vol. 24, pp. 1606-1614, 2011.

[17] M. Tarafdar, and S. Qrunfleh, "Examining tactical information technology - business alignment," Journal of Computer Information Systems., vol. 50, pp. 107-116, 2010.

[18] H. T.Wagner, T. Weitzel, J. Frank, and T.Weitzel, "IT Business Alignment and IT Usage in Operational Processes: A Retail Banking Case," in Proc. The Hawaii International Conference on System Sciences, 2006, p. 1-9.

[19] L. K. Roses, J. C. B. Brito and G. J. D. L. Filho, "Conversational competences model for information technology and business strategic alignment," Journal of Information Systems and Technology Management., vol. 12, pp. 125-144, 2015.

[20] J. Luftman, "Assessing Business-IT Alignment Maturity," Communications of the Association for Information Systems. vol. 4, pp. 1-51, Dec. 2000.
[21] M.T.M.C. Martins, "Diálogo e interações face a face:a força da oralidade na comunicação interna", Revista Organicom.,vol. 10, pp. 184-198, 2013.

[22] R. Echeverria, Ontología Del Lenguaje, 1st ed. Buenos Aires, 2008.

[23] J. Coertze, and R. V. Solms, "Towards a Cybernetics-Based Communication Framework for IT Governance," in Hawaii International Conference on System Sciences, 2015. p. 4595-4606.

[24] K.V.D. Heijden, "The Art of Strategic Planning, 2nd ed., Chichester, England: John Wileys \& Sons", 2005.

[25] D. L .Kincaid and E.M.Rogers, Communication Networks towards a New Paradigm for Research, London-England, The Free Press, 1981.

[26] A. M. Johnson, and A. L. Lederer, "The Effect of Communication Frequency and Channel Richness on the Convergence between Chief Executive and Chief Information Officers" Journal of Management Information Systems. vol. 22, pp. 227-252, Fall. 2005.

[27] W. B. Gallie, Peirce and Pragmatism, New York: Dover, 1966.

[28] R. LV, Z. Zhao, X. Chen and L. He, "Shared Knowledge and Shared Understanding between $\mathrm{CIO}$ and Top Management Team: A Literature Review," in The 19th International Conference on Industrial Engineering and Engineering Management, 2013. p. 13751381.

[29] M. C. Charaf, C. Rosenkranz, and R. Holten, "Assessing language quality in the information systems development process - a theoretical approach and its application," in Proc ICIS 2010, 2010, paper 145.

[30] A. Alsolamy, U. Khan, and P. Khan, "IT-business alignment strategy for business growth," in International Conference on Computing for Sustainable Global Development, 2014. p. 364-366.

[31] H. A. Smith, and J. D. McKeen, "Developments in practice XXXVI: How to talk so business will listen and listen so business will talk," Communications of the Association for Information Systems., vol. 27, pp. 207-216, Aug. 2010.

[32] E. Karahanna, and D. S. Preston, "The Effect of Social Capital of the Relationship between the CIO and Top Management Team on Firm Performance," Journal of Management Information System, vol. 30, pp. 15-56, 2013.

[33] M. Monteiro de Carvalho, "An investigation of the role of communication in IT projects," International Journal of Operations \& Production Management., vol. 34, pp. 36-64, 2013.

[34] S. Miller, "Social Capital and Alignment between Business and IS A Deep Dive into the Impact of Trust," in UK Academy for Information Systems Conference Proceedings 2015, 2015, paper 24.

[35] J. Kuruzovich, G. Bassellier and V. Sambamurthy, "IT governance processes and IT alignment: Viewpoints from the board of directors," in Proc. Hawaii International Conference on System Sciences IT, 2012. p. 5043-5052.

[36] A. M. Johson, and A. L. Lederer, "CEO/CIO Communication and the strategic grid dimensions," Tan, AW K, \& Theodorou, $P$. Strategic Information Technology and Portfolio Management. UK: IGI Global, pp.206-229, 2009.

[37] A. Padukkage, J. Toland, and V. Hooper, "Implications of Environmental Uncertainty for Business-IT Alignment: A Comparative Study of SMEs and Large Organizations," in Australasian Conference on Information Systems, 2015.

[38] R. Masa'deh, B. Y. Obeidat, and R. H. Al-Dmour, "Knowledge Management Strategies as Intermediary Variables Between ITBusiness Strategic Alignment and Firm Performance," European Scientific Journal., vol. 11, pp. 344-368, March. 2015.

[39] J.Luftman, K.Lyytinen, and T.Zvi, "Enhancing the Measurement of Information Technology (IT) Business Alignment and its Influence on Company Performance," Journal of Information Technology., pp.1-21, 2015.

[40] M.Eom, K.Surinder, and A.Yayla, "Investigation of How IT Leadership Impacts IT-Business Alignment through Shared Domain Knowledge and Knowledge Integration," in Americas Conference on Information Systems Proceedings, Human Capital in Information Systems (SIGLead), 2015, paper 21.

[41] F.Rahimi, C.Møller, and L.Hvam, "Business process management and IT management: The missing integration," International Journal of Information Management., vol. 36, pp. 142-154, 2016.

[42] C.Haydamack and S.Johnson, (2008) Algning IT with Business Goals through Strategic Planning [Online]. Available at https://www.intel.in/content/dam/doc/white-paper/intel-it-aligning-itwith-business-goals-paper.pdf

[43] Q. Hu, and C. D. Huang, "Using the Balanced Scorecard to Achieve Sustained IT-Business Alignment: A Case Study," Communications 
of the AIS., vol.17, pp. 2-46, 2006.

[44] J. Ohlsson, S. Han, M. Hultin, and B. Rosenren, "How to Achieve Sustainable Business IT Alignment -- Designing a Circular Organizational Structure at SAAB," in Hawaii International Conference on System Sciences, 2015, p. 5116-5125.

[45] A. Gemino, B. H. Reich, and C. Sauer, "Plans versus people: Comparing knowledge management approaches in IT-enabled business projects," International Journal of Project Management., vol. 33, pp. 299-310, 2015.

[46] C. Jentsch, and D.Beimborn, "What Matters in Business/IT Shared Understanding? Development of a United Construct," in Twenty Second European Conference on Information Systems, 2014. p. 1-9.

[47] V. McKinney, K. Yoon, and F. Zahedi, "The measurement of Webcustomer satisfaction: An expectation and disconfirmation approach," Information Systems Research., vol. 13, pp. 296-315, 2002.

[48] A. Padukkage, J. Toland, V. Hooper, "Alignment of information technology strategy with business strategy in an uncertain environment" in 25th Australasian Conference on Information Systems, 2014. 